\title{
Estimation of short-term and medium-term survival from sudden cardiac death based on the initial rhythm
}

\section{Estimativa de sobrevivência a curto e médio prazo de morte cardíaca súbita com base no ritmo inicial}

\author{
DOI: $10.46932 / \mathrm{sfjdv2n4-081}$
}

Received in: March 1st, 2021

Accepted in: May 30th, 2021

\author{
Mercedes Ahmann \\ ${ }^{1}$ Doctoral School of Health Sciences, Faculty of Health Science, University of Pécs, Pécs, \\ Hungary \\ Mercedes Ahmann PhD student, Doctoral School of Health Sciences, Faculty of Health Science, \\ University of Pécs, Vörösmarty Str. 4, H 7621 Pécs, Hungary, \\ email: ahmann.mercedes@gmail.com
}

\section{Csaba Bálint}

Doctoral School of Health Sciences, Faculty of Health Science, University of Pécs, Pécs,

Hungary

\author{
Attila Kónyi \\ Heart Institute, Medical School, University of Pécs, Pécs, Hungary \\ Zsófia Verzár \\ ${ }^{1}$ Doctoral School of Health Sciences, Faculty of Health Science, University of Pécs, Pécs, \\ Hungary
}

\begin{abstract}
Introduction: Sudden cardiac death (SCD) is a clinical syndrome defined as: sudden, premature, natural death from cardiogenic causes in a cardiac patient or a person without known cardiac disease, preceded by sudden loss of consciousness and occurring within one hour of the onset of acute symptoms. (3). According to published literature, the incidence of sudden cardiac death ranges widely (15-48\%), depending on geographical and demographic indicators.

Objective: The aim of our study was to investigate short-term and medium-term survival after resuscitation in patients with sudden cardiac death.

Methods: data from patients in two groups of sudden cardiac death were compared at hospital discharge and at 1 and 3 months after hospital discharge. We compared data from 92 patients who suffered a SCD between 1 January 2016 and 31 December 2017. Data from patients who had a proven shockable (I) or non-shockable (II) incipient rhythm following SCD were included. The main endpoint was the comparison of mortality between the two groups.

For statistical analysis, we used a T-test and ANOVA to compare the data. Our exclusion criteria included inaccurate documentation and uncertain rhythm.

Results: $62 \%$ of patients in the shock group had a significantly higher survival at all three observed time points than in the non-shock group.

Conclusion: In our study population, the hypothesis that patients with a shockable rhythm in SCD have significantly better survival than those without shockable rhythm was confirmed by several studies. Our patients had significantly higher survival both at hospital discharge and at day 30 survival.
\end{abstract}


Keywords: sudden cardiac death, ventricular arrhythmias, survival.

\section{RESUMEN}

Introducción: La muerte súbita cardíaca (MSC) es un síndrome clínico que se define como: la muerte súbita, prematura y natural por causas cardiogénicas en un paciente cardíaco o en una persona sin enfermedad cardíaca conocida, precedida de una pérdida súbita de conciencia y que se produce en la hora siguiente al inicio de los síntomas agudos. (3). Según la literatura publicada, la incidencia de la muerte súbita cardíaca varía ampliamente (15-48\%), dependiendo de indicadores geográficos y demográficos. Objetivo: El objetivo de nuestro estudio fue investigar la supervivencia a corto y medio plazo tras la reanimación en pacientes con muerte súbita cardíaca.

Métodos: Se compararon los datos de los pacientes de dos grupos de muerte súbita cardíaca al alta hospitalaria y a los 1 y 3 meses del alta hospitalaria. Se compararon los datos de 92 pacientes que sufrieron una MSC entre el 1 de enero de 2016 y el 31 de diciembre de 2017. Se incluyeron los datos de los pacientes que tenían un ritmo incipiente demostrable (I) o no demostrable (II) tras la MSC. El criterio de valoración principal fue la comparación de la mortalidad entre los dos grupos.

Para el análisis estadístico, se utilizó una prueba T y un ANOVA para comparar los datos. Nuestros criterios de exclusión incluyeron la documentación inexacta y el ritmo incierto.

Resultados: El 62\% de los pacientes del grupo de choque tuvo una supervivencia significativamente mayor en los tres puntos temporales observados que en el grupo de no choque.

Conclusión: En nuestra población de estudio, la hipótesis de que los pacientes con ritmo desfibrilable en la ECF tienen una supervivencia significativamente mayor que los que no tienen ritmo desfibrilable fue confirmada por varios estudios. Nuestros pacientes tuvieron una supervivencia significativamente mayor tanto al alta hospitalaria como al día 30 de supervivencia.

Palabras clave: muerte súbita cardíaca, arritmias ventriculares, supervivencia.

\section{INTRODUCTION}

The WHO Lancet 2001 prediction that by 2020 ischaemic heart disease will be the leading cause of death worldwide seems to be proving true. (1) Around half of cardiovascular deaths are sudden unexpected cardiac (arrhythmia) deaths, which currently account for around 17 million deaths worldwide each year, and in Hungary, according to KSH (Central Statistical Office) data, caused the deaths of more than 17,000 people in 2018. (2) Sudden cardiac death is a clinical syndrome, which is most commonly defined as sudden, premature, natural death 9from cardiogenic causes in a person with or without known heart disease, preceded by sudden loss of consciousness and occurring within one hour of the onset of acute symptoms. (3). Over the past 20 years, there have been many innovations in the care of SCD, and resuscitation protocols have been developed and changed, yet mortality rates have not improved significantly. The incidence of SCD ranges from 15-48\%, depending on geography and demography. Age differences are observed in terms of aetiology. In young athletes, there is usually a congenital or hereditary disease such as cardiomyopathies, congenital coronary anomalies, WPW, Brugada syndrome, most of which are very rare. In the elderly (over 60 years), coronary artery disease, heart failure and valve disease are the most common underlying causes of SCD. In terms of the other aetiology of the 
disease, men are not considered to be a risk factor, as the incidence is 2- 3 times higher in men, but SCD can be caused by disturbances in the electrolyte balance, activation of the autonomic nervous system or even by the proarrhythmic effect of antiarrhythmic drugs. Risk factors for SCD are similar to those for coronary artery disease, such as high blood lipids, hypertension, smoking, fiscal inactivity, obesity, cu age, elevated serum CRP, excessive alcohol consumption, and a positive family history of coronary artery disease and myocardial infarction. (4) The Hungarian Resuscitation Society, in accordance with international recommendations, revises every 5 years the basic and advanced resuscitation protocols, according to which rhythms detected in the background of sudden cardiac death can be classified rheanimatologically into two groups, shockable (ventricular tachycardia, ventricular bradycardia) and non-shockable (asystole, pulseless electrical activity), according to whether or not they can be terminated by defibrillation. (5) From the point of view of the time window, SCD requires rapid care, as even brief hypoperfusion can cause irreversible brain and myocardial and target organ damage. In addition to artificial maintenance of circulation, great emphasis should be placed on identifying and treating reversible causes (6). Survival is influenced by many factors, including the time between the onset of clinical death and the first treatment, the patient's general condition, underlying medical history and the classification of the inical rhythm, which has been studied by several studies and which we have supported. (4) Postresuscitation care is also of great importance, as the 24 hours after SCD are very important for survival. (7). In the case of sudden cardiac death, acute care varies according to the initial rhythm. While in shockable rhythms, even a DC can rapidly eliminate a life-threatening arrhythmia, more complex interventions are required for non-shockable rhythms. In non-shockable rhythms, in addition to basic and advanced resuscitation, efforts should be made to detect and address any aggravating reversible causes such as tamponade, tensional pneumothorax, toxin effects, thromboembolism, hyper- or hypokalemia, hypovolemia, hypothermia, hypoxia (4H, 4T) (5).

\section{MATERIAL AND METHOD}

In our retrospective study we used data recorded by the Emergency Department (ED) of the University of Pécs. We conducted our scientific work among patients admitted to the ED from 1 January 2016 to 31 December 2017 and who had suffered cardiac death of probable cardiological origin. In our study, we selected 92 patients and then followed up 81 patients according to our exclusion criteria. We excluded patients in whom we found incomplete documentation and those in whom the classification of the incipient rhythm was not clearly established. The 81 patients finally selected were divided into two groups, shockable and non- shockable, according to the resuscitation protocol. The source of our data was University Medical Database and the Ambulance Emergency Service documentation provided to 
the ED.

During data collection, particular emphasis was placed on the analysis of risk factors, which are summarised in Table 1.

The aim of our study was to compare short- and medium-term survival between the shock and non-shock groups. We examined survival rates at hospital discharge, 1 month and 3 months. Statistical analysis was performed with SPSS 20.0 using t-test and ANOVA.

\section{RESULTS}

A total of 92 patients were included in the study, and 81 patients remained in the study after the exclusion criteria were taken into account. Of these, 62 had a shockable rhythm and 31 had a nonshockable rhythm, for a percentage distribution of $62 \%$ vs $38 \%$. There were no differences in demographics and underlying conditions between the two groups. The mean age of the non-shock group (63.4) was higher than that of the shock group (55.2), which was in line with the literature. The proportion of people aged 60 and over was thus $70 \%$ in the non-shock group and $58 \%$ in the shock group, i.e. significantly higher in both groups. The gender distribution was dominated by men in both groups. Group I was 34/16, Group II 17/14. This is detailed in Table 2. We compared the two groups in terms of risk factors but found no significant difference between the two groups. The most striking numerical difference was for hypertension and smoking in favour of the shock group, but no significant results were obtained. We also looked at positive family history, obesity, diabetes and lipid levels, but there was no significant difference between the two groups in any of these. We were also interested in some aspects beyond the study objectives that might be informative in terms of estimating survival. We looked at the association between time to first care and survival and there was no significant difference in resuscitation times between the two groups in either case, although return to spontaneous circulation was higher in patients with non- shockable rhythms. The main endpoint of our study was to examine short- and medium-term survival. Our results showed that even in-hospital survival was significantly higher in the shockable rhythm group than in the non-shockable group (62\% vs. $38 \%, \mathrm{p}=0.0001)$. Similar results were obtained for 1 -month survival ( $54 \%$ vs. $16 \%$, p=0.0004). We were unable to examine 3 -month survival because only 1 person remained in the non-shock group, making the results statistically insignificant, but the numbers are still sufficiently informative. These data are summarised in Table 3.

Moving beyond the endpoints, we were interested to see how the number of patients undergoing PCI in the study population evolves and to what extent coronary artery disease underlies SCD. In the shock group, 50 patients underwent PCI, of whom 37 were diagnosed with coronary artery disease and 13 with other heart disease. In the non-shock group, 31 people underwent PCI, of whom 27 were 
diagnosed with coronary artery disease and 4 with other heart disease. Of the 31,18 had a previous PCI and another interesting finding was that cardiomyopathy was significantly higher in this group. $(\mathrm{p}=0.003)$ Table 4 shows the data summarised in relation to PCI. We also looked at the one-year survival in this population and found that only 6 of the original sample were alive at one year, a survival of $7 \%$.

In the population we studied, the hypothesis, which has been supported by several studies, that in the case of SCD, patients with shockable rhythms have significantly better survival rates than those without shockable rhythms, was confirmed. Over the past 20 years, there have been many developments and changes in the protocols of care for sudden cardiac death, but despite this, mortality rates have not improved significantly. A study in 2011 found that the non-shockable group had a higher number of elements of the incipient rhythms recorded in the SCD. $(8,10)$ In our study, the proportion of those with a shockable rhythm was higher, but survival rates were in line with previous studies, showing that survival rates for those with a non-shockable rhythm were worse than for those with a shockable rhythm. Our research at the University of Pécs also clearly shows the importance of the initial rhythm, as a patient with a shockable rhythm has a much better chance of short- and medium-term survival than a patient with a non-shockable rhythm. Looking at the literature, there have been several studies on this topic, with Tatsuma Fukuda and colleagues and Nadine and colleagues reporting similar results in international studies. There has been a previous study in Hungary, which has been referred to in several places, and a study by Tímea Szigethi and colleagues at the Városmajor Heart and Vascular Clinic, Semmelweis University, Budapest, also supports the previous findings. $(4,9,10,12)$.

Among the factors influencing survival identified in the European Resuscitation Society guidelines 2010-2015, the immediate circumstances of resuscitation are prominent. Among them, the time from the moment of circulatory collapse to resuscitation and the duration of resuscitation are important. (5).

To summarize our study, if we look only at the number of elements, 9 of the 92 patients included remained at the 3-month follow-up. Looking at the number of patients controlled at each time point, we can conclude that in the shock group, we observed more favourable mortality data at all three time points examined. The shock group had a significantly higher hospital survival (62\%) than the non-shock group (38\%). This was also true for the 1st month (54\% vs $16 \%$ ) and 3 month control (60\% vs $20 \%)$. We could not draw far-reaching conclusions about 3-month survival because only 1 patient remained in the nonshock group. We can therefore conclude that the initial rhythm of SCD is highly predictive of short- and medium-term survival. Both the literature and our own research suggest that shockable rhythm is a 
prognostically positive factor in SCD. 


\section{LITERATURE}

1 BernW, BöttigerMDa, ChristophBodeMDbc, et al. Efficacy and safety of thrombolytic therapy after initially unsuccessful cardiopulmonary resuscitation: a prospective clinical trial, The Lancet, Volume 357, Issue 9268, 19 May 2001, Pages 1583-1585

2. https://www.ksh.hu/docs/hun/xstadat/xstadat_eves/i_wnh001.html 2019.05.16

3. Préda I, Czuriga I, Sweet I, et al. Sudden cardiac death, In. Budapest: Medicina Könyvkiadó; 2010. pp. 625-635.

4. Szigethi Tímea, Pileczky Dávid, Pap Zsófia, et al. Association between long-term survival and inical rhythm in sudden cardiac death, Cardiologia Hungarica 2017; 47: 30-33.

5. Nolan JP, Soar J, Zideman DA, et al. Overview of sudden cardiac arrest and sudden cardiac death, UpTodate 2014. European Resuscitation Council Guidelines for Resuscitation 2010 Section 1. Resuscitation 2010; 81: 1219-1276.

6. Priori SG, Blomström-Lundgvist C, Mozzanti A, et al. ESC Guidelines for the management of patients with ventricular arrhythmias and the prevention of sudden cardiac death. European Heart Journal 2015, 36: 2793-2867.

7. Rittemberg JC, et al. Post-cardiac arrest management in adults. upToDate 2014.

8. Nolan JP. Optimizing outcome after cardiac arrest. Current Opinion on Critical Care 2011; 17: 520526.

9. Kitamura T, Iwami T, Kawamura T, et al. Nationwide improvements in survival from out-ofhospital cardiac arrest in Japan. Circulation 2012; 126: 2834-2843.

10. Goto Y, Maeda T, Nakatsu-Goto Y. Prognostic implications of con vertion from nonshockable rhythms in out-of-hospital cardiac arrest. Critical Care 2014; 18: 528.

11. Verzár, Zs ; Keresztfalvi, A ; Ghosh, S ; Szekeres, A ; Bertalan, A ; Arató, E ; Kollár, L Risks of Carotid Endarterectomy Anaesthesia: Comp arison of four different methods Perfusion-germany $19: 5$ pp. 166-170. , 5 p. (2006)

12. Rashed, A ; Gombocz, K ; Alotti, N ; Verzar, Z

Is sternal rewiring mandatory in surgical treatment of deep sternal wound infections?

Journal of thoracic disease $10: 4$ pp. 2412-2419. , 8 p. (2018) 
Tables

Table 3 Comparison of the shock and non-shock group by risk factors

\begin{tabular}{|l|c|c|c|}
\hline \multicolumn{1}{|c|}{ Risk factors } & Shock & Non-shock & $\mathrm{p}$ \\
\hline Blood fat values & 20 people (40\%) & 12 people (38\%) & 0.689 \\
\hline High blood pressure & 37 people (75\%) & 24 people (78\%) & 0.721 \\
\hline Smoking & 36 people (73\%) & 23 people (73\%) & 0.696 \\
\hline Obesity & 29 people (58\%) & 18 people (59\%) & 0.712 \\
\hline Diabetes & 13 people (26\%) & 11 people (35\%) & 0.271 \\
\hline Positive CV history & 13 people (26\%) & 8 people (27\%) & 0.269 \\
\hline
\end{tabular}

Table 5 Demographic data in the shock and non-shock groups

\begin{tabular}{|l|c|c|}
\hline & Shock & Non-shock \\
\hline Average age (years) & $55.2 \pm 28.2$ & $63.4 \pm 18.7$ \\
\hline Percentage of over 60s & $58 \%$ & $70 \%$ \\
\hline $\begin{array}{l}\text { Gender distribution } \\
\text { male/female }\end{array}$ & $34 / 16$ & $17 / 14$ \\
\hline
\end{tabular}

Table 3 Survival data in the shock and non-shock groups

\begin{tabular}{|l|c|c|c|}
\hline & $\begin{array}{c}\text { Group to be } \\
\text { shocked }\end{array}$ & $\begin{array}{c}\text { Group not to be } \\
\text { shocked }\end{array}$ & $\mathrm{p}$ \\
\hline Hospital survival & $62 \%$ & $38 \%$ & $\mathrm{p}=0.0001$ \\
\hline 1 month survival & $54 \%$ & $16 \%$ & $\mathrm{p}=0.0004$ \\
\hline 3 months survival & 0 persons & 1 person & not assessable \\
\hline
\end{tabular}

Table 3.1 Data on patients undergoing PCI

\begin{tabular}{|l|l|}
\hline \multicolumn{1}{|c|}{ Shock } & \multicolumn{1}{|c|}{ Non-shock } \\
\hline 50 PCI & 31 PCI \\
\hline 37 coronary artery disease & 27 coronary artery disease -> 18 previous PCI \\
\hline 13 other heart disease & 4 other heart disease \\
\hline & Cardiomyopathy significantly higher \\
\hline
\end{tabular}

